\title{
Dispatches from the Frontline: Using pro-poor foresight to influence decision-making
}

\author{
AIDAN EYAKUZE \\ AND \\ ARTHUR MULIRO
}

\section{Upfront}

\begin{abstract}
In the Horn of Africa's very recent past, drought events that were predicted have resulted in preventable famine and humanitarian catastrophe. During the last decade, careful observers predicted the financial crisis that led the Great Recession out of which the world economy continues to emerge. Why is the response to such early warning often so late or inadequate? Under what circumstances and in what contexts is foresight effective in influencing decisions and action? This brief report begins a reflection on these issues. Using the experience of a selection of the Rockefeller Foundation's Searchlight initiative partners around the world, it reflects on how foresight has attempted to influence policy and action, some of the techniques used and proposes some of the lessons and observations that can be drawn from these experiences.
\end{abstract}

KEYWORDS foresight; public policy; development; Rockefeller Foundation; Searchlight

\section{Introduction}

\section{Foresight ignored? Famine assured!}

The drought-related emergency in 2011 was the fourth such crisis to affect the Horn of Africa region in a decade. It affected an estimated twelve million people. A year later, 18 million people were affected by a similar crisis, the third in just eight years. These are reported in a recent Chatham House report entitled Managing Famine Risk - Linking Early Warning to Early Action. It finds that advance knowledge of an impending food shortage resulting from a severe drought seems to do little to galvanize early action, leading to the onset of a serious famine that affect millions.

Why did the authorities not act to prevent a drought from becoming a famine? Managing Famine Risk suggests a number of reasons (Bailey, 2013):

- famine early warning systems have a good track record of predicting food crises but a poor track record of triggering early action;

- these 'delay dynamics' are magnified by a disparate collection of responders and deep accountability deficit;

- for governments, political risk trumps humanitarian risk;

- for donors and national governments delay is often a politically rational strategy. 


\section{Eyakuze and Muliro: Dispatches from the Frontline}

In summary, inaction or delayed action is politically expedient when the costs of acting may be deemed too high (by making it explicit that a section of the country's population is starving) and there are few sanctions domestically or internationally for delaying the response (vulnerable populations are politically unimportant). Might this be the case in other areas of public policy and decision-making? If so, can foresight offer any relief?

\section{Purpose of this report}

Following four years of the Searchlight initiative supported by the Rockefeller Foundation, it was worth exploring a similar question. How has foresight influenced policy? What has been the experience of the Searchlight partners? What are some of the lessons and observations that can be drawn from these experiences? Four Searchlight partners were interviewed to provide insight into their experience: Centre for Democracy and Development (CDD) (Nigeria and West Africa), FORO Nacional (Peru/South America's Andean Region), Noviscape (Thailand and South Asia) and the South African Node of the Millennium Project (Southern Africa). This is a consolidated report of the interviews. It outlines some specific applications of foresight, the techniques used, the outcomes they achieved and the lessons that emerge. Three concluding observations are provided.

\section{Foresight applications and outcomes}

\section{Influencing development planning for a South African municipality}

In South Africa, foresight was used to provide insight on strategic choices that need to be made by decision-makers who are planning for the longterm future sustainability of the King Sabata Dalindyebo (KSD) municipality. A primary objective of using foresight was to raise awareness of, and build practical experience and local capacity with, long-term scenario methodologies as a tool to inform KSD's municipal strategic planning and implementation processes. The municipality has been trying for a long time to convince national authorities and potential investors that it had a vision and plan for its growth and development. It sought in particular to attract a significant amount of investment capital from a national government programme aimed at enhancing public and private urban development investment in township areas in South African cities so as to improve the quality of life of township residents.

The foresight process and resulting scenarios succeeded in generating a strong sense of buy-in from participants and, most importantly, the municipality's leadership. They believed that this process pulled together all of the strands and made a compelling long-ranged argument about where they were going. Since it had considered alternatives and risks, and how these influenced KSD's short- and medium-term plans, it resulted in a strong sellable proposition. The municipal authorities used the scenarios to create a powerful presentation that they incorporated in an aggressive campaign to market the municipality. They succeeded in securing large financial commitment from the Presidency at the national level. They were also able to engage effectively with province and other stakeholders, something they had not succeeded in doing before this exercise.

\section{Challenging the assumptions of a local government in Lima, Peru}

In Peru, foresight was used to influence the response of a local government in Lima with respect to a community of marginalized people who were being relocated to a new housing project. In a forward-looking workshop conducted by FORO two key community concerns were raised. First, the community demanded that they be provided with bilingual teachers who could translate and transmit the culture to their children. Second, they did not want to live in apartments like normal city residents and demanded a community centre provided that would maintain their social cohesion. These key requests challenged the local government's assumptions that offering the more money was sufficient incentive for them to move to new housing. 


\section{Raising the issue of urban settlements and right to housing in Nigeria}

In Nigeria, the CDD used the trend monitoring and horizon-scanning technique to bring a couple of social problems to the attention of policymakers. In the area of urbanization, CDD's investigation of a Lagos informal settlement called Dust Bin Estate brought the issue to the fore. CDD has worked with several government institutions, and with Amnesty International on a new project that is dealing with those kind of informal settlements and people's human rights and their rights to urbanization and housing.

\section{Inserting science, technology and innovation (STI) policy in Thailand's election campaigns}

In Thailand, mainstream policymakers make little use of horizon-scanning techniques and outputs. The mainstream academic community seems a little sceptical about these methods of policy interrogation. However, the foresight work and recommendations around science, technology and social change has recently informed and been incorporated into a national STI policy. Even more interestingly, in Thailand's gubernatorial election campaigns, the country's largest parties adopted these foresight-driven STI recommendations as part of their elections manifestoes and campaigns.

Given the lukewarm reception by policymakers and scepticism by the academic of foresight methods, it is noteworthy that politicians recognized at least the instrumental value of incorporating elements of analytically robust foresight in their election campaigns.

\section{Techniques}

\section{Securing political permission for and participation in the process}

In order to make the scenario-building process for KSD genuinely multi-stakeholder, the team started by securing the political permission to proceed. The municipality's executive mayor and the city manager were invited to engage in the process. They were persuaded to see it as a stakeholder 458 process rather than one driven by the public sector and to participate as ordinary citizens, despite the offices they held. This approach resulted in a highlevel of buy-in and reduced the political resistance to the process. It also bought the attention of the local people. The very fact that an executive mayor made time to comment or open a session encouraged their own engagement with the scenariobuilding process.

\section{Using what is already on the table}

The process in South Africa took on board all of the short-term or medium-term plans that had already been created, the five-year plan that has already been specified or a vision that has already been drawn up, the initiatives and people who were already doing things. Treating these inputs as an integral part of the knowledge and experience landscape helped to stretch participants while also engaging with their contemporary planning realities.

\section{Using clowns to animate an innovative and inclusive engagement process}

In Peru, some innovative but less intrusive techniques were used in the process of engaging the marginal and vulnerable populations public in foresight activities. Using clowns to lead and animate the scenario-building process captured everyone's attention. The clowns facilitated the meaningful participation of children in the scenarios-building process and made it a more powerful experience. It also made it a good entry point for dialogue with local government authorities.

\section{Using simple techniques and the demonstration effect}

Recognizing that it can be very difficult to persuade the local government to experiment, the team in Lima, Peru used simple and less intrusive foresight techniques (ask the children about their future). These encouraged people to be more open to the process and its outcomes.

Given that the novel and creative initiative came from 'outside' government it may have enhanced the probability that it would influence 


\section{Eyakuze and Muliro: Dispatches from the Frontline}

policy decisions. It seems to have provided a safe space for government to observe the practice and outputs of foresight without their having to commit public resources to either of the two elements. The Lima team is putting more effort on doing things outside the government and then using the outcomes from these processes to influence policy.

\section{Placing the issues into the public conscience}

The West African team used the print and electronic media to place the demolition of informal settlements in the public's consciousness so as to use public awareness and moral suasion to influence an official decision. The exploration of the informal settlements in an issue of the trendmonitoring newsletter was followed up by video footage and engagement with various media outlets. The issue was highlighted in more than 30 articles and electronic media mentions in Nigeria. The resulting interest from international media houses, foreign embassies, international NGOs such as Amnesty International and domestic institutions such as Nigeria's National Human Rights Commission led to the halt of the demolitions and evictions of informal settlements.

\section{Emerging lessons}

\section{The intention to embed foresight capacity in South Africa's National Planning Commission ...}

One of the things specifically that was designed from the beginning of the Searchlight process in South Africa was the engagement with the Presidency through the National Planning Commission. Through specific training opportunities on tools and methods, the aim was to embed the capacity to carry out and use foresight within the secretariat of the Commission.

\section{... did not quite work out as planned}

Despite the assumption, or expectation that public planning institutions can and ought to be doing foresight, the reality is that staff are constantly being pulled into other priority activities. They barely had time to read the trend monitoring newsletters, and none at all, to do trend monitoring and horizon scanning on an ongoing and systematic basis. Their staffing numbers would have had to increase many times over, and it was unclear whether there was any willingness within the organization to invest in which was essentially viewed as an optional extra to which resources did not need to be dedicated. In the final analysis, the foresight training conducted by the South African team resulted in some goodwill, but it did not result in embedding foresight capacity within the Planning Commission machinery.

\section{A policymaker's immediate reality overshadows a more distant possibility}

Part of the challenge was convincing institution of the need to balance broad scan, knowledge and awareness of interesting and important futures issues and signals with the pressure of the immediate that are the reality in most public service environments - the 'short-termism' of administration. Furthermore, there is a sense in the South African public service that there has been enough thinking and planning, and that government ought to really be in implementation mode.

\section{The 'pendulum swing' between extremes of planning and implementation}

Relatedly, there was a sense that when government realized that it had failed to accomplish a particular goal, there was a swing to the opposite end of the planning and implementation continuum. The 'pendulum swing' was between too much planning and no implementation, to the opposite extreme of all implementation and no planning. Ironically, even during the process of developing South Africa's first national development plan there was little appetite for discussing how long-range thinking is done well. People did not want to talk about methods and process, preferring to demand how plans could spell out what ought to be done immediately. 


\section{Foresight silos with little vertical alignment}

The South African Searchlight team did a small study recently that showed that as much as South Africa has done a significant number of long range plans and strategies, there was a lack of vertical alignment between them. The study examined a series of long-range plans that were being done at the city, provincial and national levels on the same or similar issues. When these were integrated, the outcome revealed a set of very different outlooks within the various levels of government, despite the fact that they were looking at the same space and the same issues.

\section{Invest in staff for the long term}

In an echo of the South African team's effort to build the capacity do foresight within government, Peru's team recognized the value of investing in their staff capacity for the long-term. During the Searchlight process, a small group of assistants were trained on trend monitoring and horizon scanning, but for what were felt to be relatively short six-month periods. The team realized that a longer training period, as much as three years, would have been more valuable in expanding the range and deepening the pool of people with foresight skills.

\section{Deep subject knowledge enhances the power to influence policy}

The Searchlight process in Peru (and indeed around the world) started as a low-profile research process. Its potential to influence policy and decision was not a major goal. However, after 18-24 months of trend monitoring and horizon scanning, the team recognized that it had a critical mass of researchers who had built up a strong knowledge base across a series of subjects, contained in a year's worth of newsletters and signals. An understanding of the advantage that forward-looking research gave them, led to a more aggressive engagement with topics such as science and technology in the second year of the Searchlight influence within Peru's national council of science and technology.

In addition, the team in Peru has partnered with the country's National Strategy Planning Centre (NSPC). Two of the team's researchers led the process of reviewing Peru's forward-looking plan that examined the trends happening in Peru including demographics and the outcomes of social policy. NSPC has become foresight champion, committed to promoting the use of foresight within the public sector. While it has some significant capacity constraints, the NSPC is working hard to growth its influence in the public policy space and FORO is supporting it by offering tools and techniques, information and researchers.

\section{Enhancing the credibility of foresight methodologies and outputs}

In West Africa, one challenge was to enhance the credibility of foresight outputs by enhancing the credibility of the methodology that produces them. There is a growing number of providers of futureoriented analysis such as scenario building, but it is not clear how the users of such analysis ought to differentiate between good and bad quality work. Furthermore, if national institutions are to be persuaded to invest in building such capacity internally, they must be able to 'know what they are buying'. Some form of accreditation or certification of foresight practitioners could help build the confidence among policymakers that the analysis and advice they are receiving is based on sound methodology, and forms a solid basis on which to make decisions.

\section{Technical training is vital}

Relatedly, the ability to structure research, analysis and written products from a futures perspective requires a combination of strong cognitive and creative abilities. These do not necessarily come naturally. They need to be surfaced, honed and channelled through training, practice and a form of apprenticeship or mentoring. Following a training workshop conducted by a South African Searchlight colleague, West Africa's CDD developed guidelines on how to write from a futures 


\section{Eyakuze and Muliro: Dispatches from the Frontline}

perspective and identify trends, and signals that may have contemporary policy relevance.

\section{Communicating foresight through journalists and the Internet}

Well-informed citizens are crucial allies for those seeking to influence policy decisions. Recognizing this, the Searchlight team in Thailand was able to interest a number of journalists in its science, technology and society theme, dubbed 'Science Space'. They conducted interviews on horizon scanning, which resulted in their work being featured in various mainstream newspapers and online news channels. Infographics that distil the essence of the horizon scanning and trend monitoring analysis and implications were posted onto Facebook, further extending the reach to journalists and policymakers. One popular Thai magazine, with a circulation of over 200,000 featured at least one of these infographics, significantly widening the reach of the Searchlight outputs. Partnerships with a group of young people who are promoting citizens digital rights, and an alternative journalism group is spreading the use of foresight further into the civil society space.

\section{Concluding observations}

Three main observations can be made from this exploration of several Searchlight partners' efforts at using foresight to inform and influence decisionmaking.

\section{Rich diversity of foresight applications, techniques and outcomes}

The first is the interesting diversity of foresight applications, techniques, outcomes and lessons that emerge. The range of issues and contexts in which foresight can be applied is unsurprisingly large and varied in both scale and scope - from assisting to design and align a municipal development plan in South Africa to inserting a STI policy dimension in a Thai political party manifesto. Foresight was also used to amplify the voices of the marginalized who wanted to maintain a sense of community as they relocated to new public housing in Lima, Peru, and to stop the demolitions of their homes in Lagos, Nigeria.

Foresight techniques ranged from the production of trend monitoring and horizon-scanning outputs to the development of scenarios. Interestingly, the trend monitoring output in Nigeria was used to galvanize public opinion in support of informal settlements. In Thailand, the example showed the use of foresight by politicians to garner votes by showcasing their understanding of and commitment to promoting innovation. In both cases, the approach was to use foresight to shape public opinion in favour of particular policy actions.

The scenarios developed for the South African municipality had the explicit goal of marshalling financial resources to invest in the area, which it was able to achieve. In Peru, using clowns to animate the scenario-development process made it uniquely inclusive of children's input and the technique's novelty helped to open dialogue with local government authorities.

\section{Foresight is about behaviour change in decision-making}

In a bid to influence decision-making, foresight tries to achieve three distinct but overlapping objectives. The first is to provide information and analysis about a particular set of issues that is new or different. The future orientation of such information is central to engaging the users' intellect and to challenging received wisdom from a fresh perspective. The second objective is to appeal to the users' normative instincts by 'expressing value judgments ... about how things should or ought to be, how to value them from a moral perspective, which things are good or bad and which actions are right or wrong' (http://www.thefreedictionary. com/normative). It does so in order to change attitudes about the specific issues at hand. Such a normative perspective is at the centre of the propoor foresight that has exercised the entire Searchlight initiative. The third objective is to catalyse a decision or action that alters the trajectory of events in order to achieve a new (and hopefully better) set of expected outcomes in the future. 
As a set, these three objectives try to change the process of decision-making in the public policy domain. Foresight ultimately emphasizes doing things differently or doing different things, or both. Given the complexity inherent in achieving systemic change, and the ever-present risk of the unintended consequences of such change, foresight can be a valuable tool of public policymaking.

The limited success that met the efforts to embed foresight capacity within South Africa's National Planning Commission demonstrates the nontrivial nature of this challenge. Given their instinct to promise policy certainty and predictability of outcomes, authorities find it difficult to properly invest in activities that challenge such instincts. Peru's NPSC may be capacity-constrained for similar reasons.

The daily reality of public service is driven by immediate imperatives than the more distant future possibilities. In other words, the future is deeply discounted from the perspective of the present. This is an inherently human trait, and foresight attempts to reduce the level of such discounting with varying degrees of success. This 'tyranny of the present' and of the need to be seen to be 'doing something' about a pressing issue may also partly explain the 'pendulum swing' between the extremes of planning and implementation that was highlighted earlier. It does not come naturally for policy actors to delay action in order to gather more information, deepen analysis, consider alternative options and understand their implications.

Furthermore, since policymaking is a political process, all efforts to influence it must be aware of this reality. The KSD municipality scenarios found traction because of the explicit effort that was made to secure political permission for, and participation in, their development. Ownership of the final outputs by the municipal authorities energized the successful marketing and investment promotion campaign that was based on the scenarios.

Shaping and channelling public opinion is an important way of influencing policy and decisionmaking. The use of video documentaries in Nigeria on informal settlement demolitions as well as journalist engagement and the posting of infographics in South East Asia are excellent examples of this direct engagement with the citizenry. In Nigeria, a coalition of domestic actors, foreign media and international organizations brought pressure to bear on the authorities. In Thailand at least one political party included STI in a recent election manifesto, probably in recognition of its public appeal.

\section{Foresight as a systematic process of sustaining a dialogue about the future}

Foresight practitioners should remain true to the bold mission of changing the world for the better by using forward analysis and perspective to influence the contemporary view of the future, and to catalyse policy change designed to improve outcomes. However, it should be expected from the outset that the process is long and arduous, with results that may initially be modest and the impact imperceptible. One major reason for this is that foresight, the decisions they inspire and the outcomes that emerge are all separated by time and, occasionally, distance.

As a tool for influencing policy and decisionmaking, foresight ought to be seen as a process rather than an event. For this reason, foresight practitioners should seek to start and sustain a dialogue within the systems in which they intervene or seek to influence. Without such sustained dialogue, the value of foresight evaporates. Recognizing this, the Project on Forward Engagement, was established by a former US government official to use foresight to change the way the entire US government engaged with the future. It is therefore a propos to conclude this report with the words of its Founder and Director, Professor Leon Fuerth:

Forward Engagement is a process of thinking systematically through the longer-range consequences of present-day policy issues and also about the consequences of future contingencies for presentday decision-making. The objective of the Project is to encourage a more profound and continuous interaction between long-range thinking and actual policy-making. 


\section{Eyakuze and Muliro: Dispatches from the Frontline}

Encouraging this development is key to better safeguarding our society from unanticipated strategic surprise and, in particular, assuring the continued ability of democratic governance to successfully deal with an increasing rate of change in every area of human activity. (http://www.forward engagement.org/).

\section{Reference}

Bailey, Rob (2013) 'Managing Famine Risk - Linking early warning to early action', April, London: Chatham House Report. 